Article

\title{
Out of Body, Loss of Self: Spiritual or Scary?
}

\author{
Elpine M. de Boer
}

Faculty of Humanities, Institute for Area Studies, School for the Study of Religion, Leiden University, 2300 RA Leiden, The Netherlands; e.de.boer@hum.leidenuniv.nl

Received: 6 September 2020; Accepted: 23 October 2020; Published: 28 October 2020

\begin{abstract}
The main aim of the present study is to investigate when "loss of self" results in scaredness or anxiety during or after an out-of body-experience (OBE). An OBE is an intense form of (bodily) self loss in which people have the impression that their self is located outside their body. In a sample of respondents reporting to have had an OBE $(n=171)$, anxiety and different conceptualizations of "self loss" were assessed. In addition, questions were asked about meaning making processes after the OBE. Results show that there was no relationship between anxiety and self loss with a relational component (i.e., mystical experiences, positive spiritual experiences). However, there was significantly more anxiety in respondents who (1) (have) experience(d) ego loss/deconstruction, (2) have difficulties to (re)turn their attention to an internal bodily state (low mindfulness) and/or (3) experience a lack of self-concept clarity. Respondents who did not succeed in making sense of their OBE experience more anxiety, more ego loss/deconstruction, lower mindfulness and higher self-unclarity. Finally, the article examines how respondents explain their OBE (by using, for instance, medical, spiritual or psychological explanations) and how and why respondents do (not) succeed in making sense of the OBE.
\end{abstract}

Keywords: out-of-body experience; self loss; spirituality; anxiety

\section{Introduction}

Religion is not only about beliefs or belonging to religious institutions but also includes personal self-transcendent experiences (cf. bonding experiences, Saroglou 2011). Various religious writings refer to experiences of a felt connectedness with something beyond the self: feelings of oneness, seeing angels, hearing voices of the divine or other signs of a "sensed presence" (cf. James [1902] 1985).

When people have special, uncommon experiences in a religious context, certain experiences may be recognized or labeled as religious experiences by a religious community (Taves 2008). However, in secular societies where fewer and fewer people belong to traditional religious institutions, people also report to have had special unusual experiences. These experiences may raise existential questions or trigger self-transformation processes.

A spiritual experience can be regarded as a self-transformation in which the boundaries between self and the environment change. The present study focuses on a particular experience in which the experience of the self clearly deviates from what is usually experienced as one's normal self: the out-of-body experience (OBE). In an OBE people have the impression that the self or their center of awareness is located outside their body (Alvarado 2000). These impressions and the perceived nature of OBEs by experiencers may confirm or challenge prior (religious, scientific, paranormal) beliefs about the body-soul, the afterlife, time, space (if interested in views on the origin of OBEs, which is not the topic of the present study; see, for instance, Alvarado's review of parapsychological and psychological research, Alvarado 2000).

The majority of unusual experiences (not only OBEs) is reported to be positive, and many people use spiritual terms to refer to their experiences (Braud 2012). However, it is important to note that 
in the current study an OBE is not a priori regarded as a (positive) spiritual experience. For some people, the OBE can be scary, a frightening experience (Wilde 2011) or it may give rise to an existential crisis, for instance because the everyday experience of "having a 'real me' that 'resides' in my body" is challenged (Aspell and Blanke 2009, p. 74, referring to Blackmore 1982).

In a broader sense than with regard to OBEs, "loss of self" or a dissolution of self-boundaries has been both related to mental illness and anxiety (e.g., pathological dissociation-type experiences-also, in particular, in OBE samples, Murray and Fox 2005; Kohls and Walach 2007) as well as to (positive) self-transcendent experiences, characterized by transient mental states of decreased self-salience and increased feelings of connectedness, such as in mystical experiences (e.g., Yaden et al. 2017). The main aim of the present study is to investigate when "loss of self" during or after an OBE may result in scaredness and anxiety. It is important to get more insight in what is meant by "loss of self" (cf. Yaden et al. 2017). For this reason, we use in the present study different conceptualizations of self loss assessed by using validated scales, as well as closed- and open-ended questions, to study people's own descriptions, understanding and possible meaning making processes after the OBE.

\subsection{Loss of Self with and without a Relational Component}

Yaden et al. (2017) make a distinction between two components of self-transcendent experiences: an annhiliational component, characterized by a "dissolution of the bodily self accompanied by reduced self-boundaries and self salience" (pp. 2-3), and a relational component "referring to the sense of connectedness, even to the point of oneness, with something beyond the self, usually with other people and aspects of one's environment or surrounding context" (p. 3). They suggest that mystical experiences involve both the annihilational and relational part (e.g., a loss of self in a greater unity) but that depersonalization episodes may involve the annhiliational part but not the relational part of self-transcendent experiences (p. 7).

An out-of-body experience (OBE) can be part of a near-death-experience (NDE), experiences that some people experience when they are close to death. Greyson (1994) emphasizes transcendental and mystical elements in his definition of near-death-experiences. OBEs may include mystical elements as well, as part of an NDE or otherwise, referring to self loss with the relational component, but an OBE can also be experienced as self loss without the relational component: purely seeing the bodily self from a distance.

Kohls and Walach (2006) have also noted the importance of distinguishing different types of experiences. They made an instrument in which four types of so-called exceptional human experiences (i.e., "experiences that touch on areas outside the common-sense reality of our everyday world", p. 126) are measured. What is relevant here is that their factor "positive spiritual experiences", that involves a relational component (example items "I am illumined by divine light and divine strength" and "A higher being protects or helps me") could be empirically differentiated in a large sample $(\mathrm{n}=700)$ from the factor "ego loss/deconsruction" (example items "a part of me dies", "my consciousness separates from by body"), that may be regarded as self loss without a relational component, and is thus solely an annihilation of the self. Spiritual practitioners, who practice meditative or spiritual techniques on a regular basis, had higher scores than non-practitioners (and a clinical sample) on both ego loss/deconstruction and positive spiritual experiences, which seems to be in line with the idea that spiritual experiences can involve an annhiliational and relational component. Only ego loss/depersonalization was significantly related to psychological distress (e.g., anxiety, depression, somatization), but, interestingly, exclusively in the spiritual non-practicing sample. Kohls and Walach $(2006,2007)$ suggest that the resulting distress may also depend on how ego loss is evaluated. Evaluation might be different for spiritual practitioners who may be familiar with temporarily ego loss or when it fits in a certain spiritual narrative (i.e., "ego death").

People who have reported an out-of-body experience and live in a secularized country (i.e., the Netherlands) are likely to be largely non-spiritual practitioners. Some of them may therefore feel scared or anxious during or after an experienced loss of self, particularly self loss without the 
relational component. More specifically, in a sample of people who reported an out-of-body experience, it is expected that there will be no relationship between "loss of self' with a relational aspect (mystical experiences or positive spiritual experiences) and anxiety (Hypothesis 1a). Only "loss of self" without a relational aspect (ego loss/de-construction) will be related to anxiety (Hypothesis 1b). In order to get more information about the nature of the respondents' out-of-body experience, we also asked the following open-ended question: "Describe your most impressive OBE".

\subsection{Loss of Self as Inflexibility to Attune or Return to an Internal State}

To further explore the relationship between "loss of self" and anxiety, it is important to delve into the concept "attention". Two psychological concepts that may be important when we are dealing with out-of-body experiences and other self-transcendent experiences are: absorption and mindfulness.

Attention plays an important role in definitions of mindfulness. For instance, Marlatt and Kristeller (1999), cited by Baer (2003, p. 68), describe mindfulness as "bringing one's complete attention to the present experience on a moment-to-moment basis". Several empirical studies have shown that mindfulness is negatively associated with anxiety and other psychopathological symptoms (Tomlinson et al. 2018). Excessive self-focus (i.e., rumination) is generally seen as something that reinforces fears and anxieties. Loss of self in the sense of being freed from the whirlpool of thoughts and feelings in which we can become entangled ("our ego") may then reduce fears and anxieties. In their discussion of mindfulness, Yaden et al. (2017) seem to mean this type of self loss, and for this reason they include mindfulness among the "self-transcendent" experiences.

Blaser et al. (2014) emphasize a different property of mindfulness that also has to do with focusing attention, but that is not (only) about a loss of the self, but rather the re-connection with the self: attuning or returning to an internal state and the bodily self. They say that "to be mindful, to look inside from within, we have to cross our self-boundary from outside to within with the location of our attention" (Blaser et al. 2014, p. 156) and "When we arrive within ourselves, we are bodily connected with our emotions, experiences and images" (Blaser et al. 2014, p. 156). Despite the differences between Yaden et al. and Blaser et al., a certain self-regulation of attention seems to be central in both descriptions of mindfulness.

Attention also plays an important albeit different role in descriptions of the personality trait absorption. Absorption (Tellegen and Atkinson 1974, p. 268) refers to individual differences in "the disposition for having episodes of 'total' attention that fully engage one's representational (i.e., perceptual, enactive, imaginative, and ideational) resources". As their attention turns inwards, perceptions, feelings, images are experienced as "sensory" experiences for people with high scores on absorption. Whether caused by an internal or external stimulus, experiences feel "real" (Lifshitz et al. 2019). Several empirical studies show a robust association between absorption and self-transcendent experiences, such as mystical and spiritual experiences (Coleman et al. 2019; Granqvist et al. 2012; Lifshitz et al. 2019).

Various authors also stress a relationship between absorption and dissociation-like phenomena (Acunzo et al. 2020; Granqvist et al. 2012). In addition, it has been shown that both the trait absorption and dissociation-like experiences relate to the occurrence of out-of-body experiences (Aspell and Blanke 2009; Alvarado 2000). According to Murray and Fox (2005), OBEs are more likely to occur in people who have a weaker sense of embodiment. Some people may have lost touch with their bodily self, never felt a connection or lost it very early in childhood. Severe anxiety or trauma(tic childhood events) can play a role in the development of dissociation and the occurrence of OBEs (Alvarado 2000 referring to (Irwin 1986)). For example, sexual abuse, a serious accident or extreme grief can make someone want to break or avoid contact with their body and inner feelings, which can result in a generalized dissociation between their sense of self and the body. Blaser et al. (2014) suggest that trauma may have consequences for the ability to be mindful or to recognize a mindful state of being: "when the self-boundary is not well defined, is blurred for example by trauma, we cannot longer be 
sure if we are inside or outside our self-boundary with the location of our attention, that is, inside or outside our innerworld, mindful or not mindful" (Blaser et al. 2014, p. 155).

In a sample of OBErs, it is expected that having difficulties to attune or return to an internal state or bodily self (low mindfulness) is associated with anxiety (Hypothesis 2a). In addition, it is assumed that high absorption (attention away from the body and the here-and-now) is positively related to mystical experiences and negatively related to (attention to here-and-now in) mindfulness (Hypothesis 2b).

\subsection{Loss of Self as a Result of Not Making Sense of the OBE}

Finally, the element "time" is important. Descriptions of self-transcendent experiences, including mystical experiences, emphasize that these are brief mental states (cf. James' criteria of mystical experience: transiency, (James [1902] 1985). So, if self-transcendent experiences are characterized as "loss of self" it is clear that we are talking about a temporarily loss of self and not an enduring or definite loss of self.

Paloutzian (2016), referring to (Paloutzian and Park 2013), calls religious and spiritual self-transformation-which can be triggered by intense experiences-a meaning-making process in which various components in the meaning system, including the self (self-schemas), change. According to the James-Boisen formula (Hood et al. 2018, p. 298), a religious experience can be considered as "the meaningful transcendence of limits of the resolution of discontent, rooted in a sense of the divine". We may understand this as follows: through the "self" that has been constructed, we encounter limitations and barriers in life (discontent) and during a self-transcending experience these limitations may disappear (resolution). It depends on the interpretation whether we call this experience religious or spiritual (Taves 2008). OBEs and NDEs have been viewed by people who have them as "turning points" in their lives, that are sometimes viewed as a "spiritual awakening" or trigger a quest for meaning (Wilde and Murray 2009, 2010). As was earlier said, for some people it can be a frightening or confusing experience (Wilde 2011). The ego aims to maintain and protect a certain conception of the self. So perhaps ego loss and changes always involve a certain amount of fear. However, after a while, a new stable self-organization should develop. It is important for people to develop a coherent self in order to be able to maintain themselves in daily life, process information and respond to the environment. Various psychological studies emphasize the importance of self-concept clarity (Campbell et al. 1996): the perception that one has a clear and coherent self (i.e., internally consistent and temporally stable). Self-concept clarity (i.e., having a clear idea of who and what I am) is usually related to psychological adjustment (Bigler et al. 2001).

An out-of-body experience is a very intense form of self loss because there is literally no more contact with one's bodily self. It can be imagined that an out-of-body experience can evoke a lot in people, perhaps metaphysical thoughts about consciousness that can change one's beliefs (i.e., body versus soul, life after death). Additionally, if people suddenly see themselves from a distance, this may evoke thoughts about "the self": "who am I actually in this world?" And "why should this happen to me right now?" It is therefore important to investigate if and how people make sense of their out-of-body experience. People who fail to make sense of the OBE may continue to experience a certain degree of self loss, as they are still looking for a new orientation in the world, a center from which they perceive reality, what they believe in and what they stand for (i.e., self-concept unclarity). In a sample of people who reported an out-of-body experience, it is therefore assumed that self-concept unclarity is related to anxiety (Hypothesis 3a) and that respondents who do not succeed in making sense of the OBE, experience more self-concept unclarity (Hypothesis 3b). To get insight in meaning making processes after the OBE and respondents' own explanations of the OBE, we also asked the following two open-ended questions: "Did you make sense of your OBE? How? Why (not)?" and "(How) do you explain this experience?" 


\section{Method}

\subsection{Procedure}

Participants were contacted by a Dutch marketing agency specialized in research and consultancy and asked to fill out a short questionnaire that was constructed by the author of this article and a philosopher specialized in the academic study of exceptional experiences. The short questionnaire included, for instance, questions about the frequency of out-of-body experiences and if they had contacted a regular or alternative caregiver. The following description of an out-of-body experience was given: "In an out-of-body experience you have the feeling that you are located outside your physical body" (cf. Alvarado 2000). Fourteen percent of the respondents (one in seven) answered "yes" to this question: "Did you have had an out-of-body experience?" Subsequently respondents who reported to have had an out-of-body experience (OBE) were asked to fill out a more elaborate questionnaire. We offered the chance to win two books about research on exceptional experiences to increase the motivation to participate. T-tests revealed that there were no differences in gender, age and education between the samples, but respondents who chose to also fill out the longer questionnaire had experienced significantly more often OBEs than respondents who did not want to fill out the longer questionnaire.

\subsection{Participants}

A total of 171 respondents from the Netherlands participated in the study. There were 89 male $(48 \%)$ and 98 female $(52 \%)$ respondents. Their age was between 18 and 87 (average age 51.4 years, $\mathrm{SD}=13.1$ years). The education level of the respondents varied from no to low education (primary school) to higher education. The majority of respondents was raised as "catholic" ( $n=53 ; 31 \%)$, "protestant" ( $\mathrm{n}=33 ; 19 \%)$ or without religious worldview. At the moment they filled in the survey, respondents mainly identified as "spiritual" ( $\mathrm{n}=36 ; 21 \%)$, "interested in meaning" $(\mathrm{n}=31 ; 18 \%)$, "catholic" ( $\mathrm{n}=29 ; 17 \%)$, "atheist" ( $\mathrm{n}=21 ; 12 \%)$, "searching for meaning" $(\mathrm{n}=21 ; 12 \%)$ and "protestant" $(\mathrm{n}=17 ; 10 \%)$. About half of the respondents claimed to have had one out-of-body experience $(49.1 \%)$, whereas others had more than one OBE. About $24 \%$ of the respondents were in a hospital during their OBE. Some respondents said that they were very near death. One third (35\%) felt mentally normal "as usual" during the OBE, others said that they felt not "entirely conscious" (19\%) or that they were "anxious" (12\%) or "happy" (8\%).

In order to increase the chance that participants would complete the questionnaire, we decided to create two random subsamples that answered a somewhat different battery of questions. Most of the questions reported in the present study were answered by all our respondents (e.g., all open-ended questions, questions about mental health), but some questions were only asked in subsample 1 $(n=82)$ and some questions were only asked in subsample $2(n=89)$. More specific information is described below.

\subsection{Measurement}

\subsubsection{Open-End Closed-Ended Questions}

After the question about the frequency of OBEs, five close-ended questions ( $1=$ yes, $2=$ no) about the aftereffects of OBEs were asked: "I got scared", "It was confusing", "It was interesting", "because of the experience, I now know something of death" and "because of the experience, I now live more intensely".

In order to get an idea of the nature of the OBE and (long-term) meaning making processes, we asked the following questions: (1) Describe your most impressive OBE, (2) Did you make sense of your OBE? ( 1 = "No", 2 = "Yes, I do now" 3 = "Yes, immediately after the OBE"). Describe how, why (not)? and (3) How do you explain this experience? 


\subsubsection{Quantitative (Scales)}

"Absorption" - a disposition for having episodes of total attentional engagement-was assessed by the Tellegen and Atkinson (1974) 34-item absorption scale (e.g., "I can be greatly moved by eloquent or poetic language", "At times I somehow feel the presence of someone who is not physically there". Responses ranged from (1) never to (5) always. These questions were answered by respondents in subsample $1(\mathrm{n}=82)$; Cronbach's $\alpha=0.94$.

"Mystical experiences" (32 items) were measured using Hood's (1975) M-Scale (e.g., "I have had an experience in which I realized the oneness of myself with all things", "I have had an experience in which something greater than myself seemed to absorb me". Responses ranged from (1) this description definitely not applies to my experience(s) to (5) this description definitely applies to my experience(s). These questions were answered by respondents in subsample $1(n=82)$; Cronbach's $\alpha=0.90$

The prevalence of "Positive spiritual experiences" ( 7 items) was measured by the first subscale of the Exceptional Experiences Questionnaire, i.e., spiritual experiences of transcending the self (EEQ, Kohls and Walach 2006). Please decide for each statement: Have you personally experienced this phenomenon or not? Example items are "Benign light surrounds me", "I feel the presence of spiritual/extraterrestrial beings". Responses ranged from $0=$ never, $1=$ seldom, $2=$ sometimes, $3=$ often to $4=$ very often. These questions were answered by respondents in subsample $2(n=89)$; Cronbach's $\alpha=0.87$

The prevalence of "Ego loss/deconstruction" was measured by a second subscale of the EEQ (Kohls and Walach 2006). According to Kohls and Walach, these experiences are presumably related to dissociation type phenomena. Example items are "A part of me dies" and "my environment seems somewhat blurred or illusory to me". Responses ranged from $0=$ never, $1=$ seldom, $2=$ sometimes, $3=$ often to $4=$ very often. These questions were answered by respondents in subsample $2(n=89)$. Cronbach's $\alpha=0.68$.

"Self-concept unclarity" was measured by six items based on Campbells' idea of self-concept clarity - the perception that one has a clear and coherent sense of self (Campbell et al. 1996). An example-item is "Generally, I have a clear idea of who and what I am" (reversed item). Responses ranged from (1) never to (5) always. These questions were answered by all respondents $(\mathrm{n}=171)$. Cronbach's $\alpha=0.80$.

Mindfulness was assessed by the MAAS (Brown and Ryan 2003). An example-item is: "I could be experiencing some emotion and not be conscious of it until some time later" (reversed). Responses ranged from (1) almost always to (6) almost never. These questions were answered by all respondents $(\mathrm{n}=171)$. Cronbach's $\alpha=0.89$.

"Anxiety" was measured using the Anxiety subscale (7 items) of the HADS (Zigmond and Snaith 1983). An example-item is "I have an anxious, tense feeling in my stomach". Items were scored on a 4-point scale (0 to 3), $1=$ never to $4=$ mostly). The maximum score is 21 . Higher scores refer to more anxiety complaints. These questions were answered by all respondents $(n=171)$. Cronbach's $\alpha=0.87$.

\section{Results}

\subsection{Descriptions of OBE and Aftereffects}

Respondents were asked to describe their "most impressive out-of-body experience". A large majority (about 60\%; comparable to Alvarado 2000, review of 11 studies) describes the experience as floating outside or seeing their physical body from a short distance, often from "above". Others provide (additional) information about where they float (e.g., far away, travelling to another dimension, through the walls) or what they perceive (e.g., seeing other people, other "selves", deceased relatives, their own funeral). See citations of examples below. 
"See how I was abused". (Woman, 49 years old)

"Lying in a bed I have the impression that I am floating upstairs. Then I have a conversation with two other selves, who were the same in appearance. I was all three of me. The conversation was about whether or not I would jump (from somewhere, to a place without a floor). After a while I became aware that I was in bed, but I couldn't move my body. After a while I was able to move again and I realized that this was a special experience". (Man, 60 years old)

"During work I came under power current for some time. It was then that I entered an avenue full of flowers. At the end of this corridor was my deceased sister-in-law, beckoning me to go back. It was then that I woke up at the ICU in the hospital". (Man, 47 years old)

"Quite difficult to choose, but the one in which I was allowed/could pick up an acquaintance to go with her to what I call the other worlds. I have been out of my body since my childhood, so I have traveled a lot and am familiar with a number of these worlds or realities". (Women, 54 years old)

A small group was explicit about how they evaluate/appreciate the OBE. For instance they used positive words (about 15\%) to describe their experiences, such as "bright light", "peaceful", "calm", "rest", "beautiful colors", "beautiful flowers". About 8\% used negative words, such as "scared", "anxious", "terrifying", "fright", fear". Some used both negative and positive words to describe their experience.

The majority of the respondents affirmed "It was interesting" (79\%), "because of the experience, I now live more intensely" (56\%) and "because of the experience, I now know something of death" $(50 \%)$. Some of the respondents said "I got scared" (22\%) or "It was confusing" (46\%).

\section{2. "Loss of Self" and Anxiety}

Table 1 shows the means, standard deviations and intercorrelations of the variables in this study, that were assessed by scales. Average scores show, for instance, that mystical experiences (e.g., felt oneness with all things) are relatively frequently reported in contrast to ego loss/deconstruction (e.g., a part of me is dying. Almost half of the respondents report that descriptions as "I have had an experience in which I realized the oneness of myself with all things" and "I have had an experience in which something greater than myself seemed to absorb me" apply to their experience, a quarter is unsure and less than a third say that these descriptions do not apply to their experiences. But we cannot be totally sure if respondents referred (only) to the OBE when they answered this question or other questions in the mysticism scale.

Table 1. Means, Standard deviations, intercorrelations regarding “Loss of Self" measures and Anxiety.

\begin{tabular}{|c|c|c|c|c|c|c|c|c|c|}
\hline & Scale & $\mathbf{n}$ & M(SD) & 1. & 2. & 3. & 4. & 5. & 6. \\
\hline 1 & Absorption (1-5) & 82 & $2.79(0.65)$ & & & & & & \\
\hline 2 & $\begin{array}{c}\text { Mystical } \\
\text { experiences (1-5) } \\
\text { Pos. }\end{array}$ & 82 & $3.33(0.64)$ & $0.40^{* * *}$ & & & & & \\
\hline 3 & $\begin{array}{l}\text { Spir experiences } \\
(0-4)\end{array}$ & 89 & $1.22(0.96)$ & a & a & & & & \\
\hline 4 & $\begin{array}{c}\text { Ego } \\
\text { loss/deconstruct } \\
(0-4)\end{array}$ & 89 & $0.70(0.53)$ & a & a & 0.19 & & & \\
\hline 5 & $\begin{array}{l}\text { Self-concept } \\
\text { unclarity (1-5) }\end{array}$ & 171 & $2.38(0.82)$ & $0.30 * *$ & 0.00 & 0.13 & $0.44^{* * *}$ & & \\
\hline 6 & $\begin{array}{l}\text { Mindfulness } \\
(1-6)\end{array}$ & 171 & $4.05(0.83)$ & $-0.23 *$ & 0.09 & 0.11 & $\begin{array}{l}-0.37 \\
* * *\end{array}$ & $\underset{* * *}{-0.53}$ & \\
\hline 7 & Anxiety (0-21) & 171 & $6.48(4.04)$ & $0.23 *$ & 0.00 & -0.07 & $0.56^{* * *}$ & $0.59 * * *$ & -0.55 \\
\hline
\end{tabular}

${ }^{*} p \leq 0.05,{ }^{* *} p \leq 0.01,{ }^{* * *} p \leq 0.001$ (two-sided). a = correlation could not be calculated because variable is only measured in one subsample. 
The majority of respondents seldom experienced positive spiritual experiences, such as "I feel the presence of spiritual/extraterrestrial beings". Inspection of the items reveals that respondents score relatively high (i.e., it is sometimes or often experienced by sixty percent of the respondents) on the following item: "a higher being protects or helps me". Additional $t$-tests revealed that respondents who, because of their OBE, "now know something about death" and "now live more intensely" had significantly more positive spiritual experiences (respectively, $\mathrm{t}=3719, p<0.0010 ; \mathrm{t}=3038$, $p<0.01$ ). In contrast, respondents who found the OBE confusing had significantly less positive spiritual experiences $(\mathrm{t}=-2422, p<0.05)$.

Some respondents suffered from anxiety complaints. However, compared to average normative data within a non-clinical sample (Crawford et al. 2001), there are no indications of more (or less) anxiety complaints in this sample of respondents with an out-of-body experience. Additional $t$-tests revealed that respondents who affirmed "I got scared" because of the OBE reported significantly more anxiety complaints $(t=2104, p<0.05)$ than respondents who deny this. Also respondents who found the OBE confusing reported more anxiety complaints $(t=2116, p<0.05)$.

As expected, there are no significant correlations between "loss of self" measures with a relational component (mystical experiences and positive spiritual experiences) and anxiety. This means that Hypothesis 1a is confirmed. In addition, the lowest row of Table 1 shows that there is a significant positive correlation $\left(\mathrm{r}=-0.56^{* * *}\right)$ between "loss of self" without a relational aspect, ego loss/deconstruction, and anxiety. This means that Hypothesis $1 \mathrm{~b}$ is supported as well. Additional $t$-tests revealed that respondents who found the OBE confusing had significantly higher ego loss/deconstruction scores $(t=2269, p<0.05)$.

Mindfulness is negatively and moderately to strongly $\left(-0.55^{* * *}\right)$ correlated with anxiety, implying that low mindfulness is, as hypothesized (Hypothesis 2a), associated with anxiety. Additional $t$-tests revealed that respondents who affirmed "I got scared" because of the OBE scored lower on mindfulness (3033, $p<0.01)$. Respondents who found the OBE interesting $(t=2052, p<0.05)$ had higher scores on mindfulness. Absorption is, in line with several prior studies, positively correlated $\left(\mathrm{r}=0.40^{* * *}\right)$ to mystical experiences and negatively and weaker related $\left(\mathrm{r}=-0.23^{*}\right)$ to mindfulness. This means that Hypothesis $2 \mathrm{~b}$ is confirmed.

Finally, Table 1 shows that self-concept unclarity is also relatively strongly correlated to anxiety. This means that Hypothesis $3 a$ is confirmed. Additional $t$-tests revealed that respondents who got scared and who found the OBE confusing experienced more self-concept unclarity (respectively, $\mathrm{t}=3033$, $p<0.01 ; \mathrm{t}=2090, p<0.05$ ). Because there are moderate to strong intercorrelations between ego loss/deconstruction, self-concept unclarity and low mindfulness, regression analyses were conducted to test their independent contribution in the explanation of anxiety. Findings from regression analyses are shown below in Table 2 . 
Table 2. (a) Regression Analysis (Enter Method) predicting Anxiety ( $\mathrm{n}=82$, subsample 1). (b) Regression Analysis (Enter Method) predicting Anxiety ( $\mathrm{n}=89$, subsample 2).

\begin{tabular}{|c|c|c|c|c|c|}
\hline \multicolumn{6}{|c|}{ (a) } \\
\hline & B & SE & $\beta$ & $\mathbf{t}$ & $p$ \\
\hline \multicolumn{6}{|l|}{ Predictor variable: } \\
\hline (Constant) & 9.010 & 3.591 & & $2.509 *$ & 0.014 \\
\hline Absorption & 0.004 & 0.019 & 0.02 & -0.230 & 0.819 \\
\hline Mystical experiences & 0.175 & 0.622 & 0.03 & -0.281 & 0.779 \\
\hline Self-concept unclarity & 1.714 & 0.508 & 0.36 & $3.375^{* *}$ & 0.001 \\
\hline Mindfulness & -1.942 & 0.573 & -0.36 & $-3.390 * *$ & 0.001 \\
\hline \multicolumn{6}{|c|}{ (b) } \\
\hline & B & SE & $\beta$ & $\mathbf{t}$ & $p$ \\
\hline \multicolumn{6}{|l|}{ Predictor variable: } \\
\hline (Constant) & 4.351 & 2.347 & & 1.854 & 0.067 \\
\hline Pos spir experiences & -0.676 & 0.319 & -0.17 & $-2.121 *$ & 0.037 \\
\hline Ego loss/deconstruct & 2.586 & 0.647 & 0.35 & $3.996 * * *$ & 0.000 \\
\hline Self-concept unclarity & 2.165 & 0.525 & 0.36 & $4.124^{* * *}$ & 0.000 \\
\hline Mindfulness & -0.949 & 0.410 & -0.20 & $-2.313 *$ & 0.023 \\
\hline
\end{tabular}

Table 2 shows that the self loss measures ego loss, self-concept unclarity and low mindfulness independently and significantly predicts anxiety. The regression models explain 43\% (Table 2a) and $52 \%$ (Table $2 b$ ) of the variance in anxiety. The relationship between absorption and higher anxiety disappears in the regression equation (Table 2a) that includes mindfulness and self-concept unclarity. Interestingly, positive spiritual experiences (Table $2 \mathrm{~b}$ ) also significantly predict lower anxiety.

\subsection{Making Sense of OBE, Loss of Self and Anxiety}

The second column of Table 3 shows that most respondents could make sense of the experience, immediately or after a while. The categorization of the qualitative material suggests that respondents who could make sense of the OBE immediately after its occurrence "assimilated" the experience in an existing belief system or that the "nature" of the experience helped them make sense of the OBE. Respondents who finally made sense of the OBE were during a longer period involved in a meaning making process, and some of them may have changed ("accommodation") their meaning making system, for instance after discussing their experience with others or finding information about the OBE. Almost twenty percent did not succeed in making sense of the OBE. Some just did not like the question and thought they did not need to make sense of it. Others still did nott understand the experience or wanted to forget it. Some respondents wanted to share their experience with others and complained that others, for example medical caregivers, did not want to talk about the OBE. 
Table 3. Did you make sense of your OBE? How/why $($ not $)$ ? $(\mathrm{n}=171)$ *.

\begin{tabular}{|c|c|c|c|}
\hline & & Example Categorization & $\mathbf{n}$ \\
\hline \multirow{4}{*}{1} & \multirow{4}{*}{$\begin{aligned} & \text { No } \\
N & =34,20 \%\end{aligned}$} & I still cannot make sense of the experience, I don't understand & 11 \\
\hline & & I don't need to make sense of it & 9 \\
\hline & & $\begin{array}{l}\text { Others (e.g., medical caregivers) didn't or don't want to talk about my } \\
\text { experience }\end{array}$ & 6 \\
\hline & & I want to forget this experience, get rid of it & 3 \\
\hline \multirow{4}{*}{2} & \multirow{4}{*}{$\begin{array}{l}\text { Yes, I do now } \\
N=66(39 \%)\end{array}$} & Re-thinking and seeking information (reading, internet, tv) & 16 \\
\hline & & $\begin{array}{l}\text { Talking to others (e.g., family, friend, physician, psychologist, } \\
\text { spiritual caregiver, paragnost, medium) }\end{array}$ & 16 \\
\hline & & Finally accepted that OBE is a valid experience, integration, go on wih & 13 \\
\hline & & Emotional process (first: grief, insecurity, fear of becoming mad) & 6 \\
\hline \multirow{5}{*}{3} & \multirow{5}{*}{$\begin{array}{l}\text { Yes, Immediately } \\
\qquad \mathrm{N}=77(41 \%)\end{array}$} & It is just a familiar, para(normal) experience & 13 \\
\hline & & Experience itself gave me the explanation, confirmation, answers & 11 \\
\hline & & It was a beautiful experience, it just had to be like this & 11 \\
\hline & & Acceptance, let it go/flow, go on with your life & 10 \\
\hline & & Experience is spiritual or fits in my belief- or meaning-giving system & 9 \\
\hline
\end{tabular}

${ }^{*}$ Answers from 134 respondents. Categories with fewer respondents were excluded. Not all respondents answered the question.

In order to test our final hypothesis, some $t$-tests were conducted to see if there were differences in loss of self and anxiety in the respondents who did $(n=137)$ and who did not $(n=34)$ succeed in making sense of their OBE. Table 4 shows that, as hypothesized, self-concept unclarity is significantly higher in respondents who did not succeed in making sense of the OBE. This implies that Hypothesis $3 \mathrm{~b}$ is confirmed. However, ego loss, low mindfulness and anxiety are also higher in respondents who did not succeed in making sense of the OBE.

Table 4. $t$-tests of Mean Difference between respondents who did or did not succeed in making sense of the OBE.

\begin{tabular}{|c|c|c|c|c|c|c|c|c|c|}
\hline \multirow[b]{2}{*}{ Variable } & \multicolumn{3}{|c|}{$\begin{array}{l}\text { (Finally) Succeeded in } \\
\text { Making Sense of OBE } \\
\qquad(n=137)\end{array}$} & \multicolumn{3}{|c|}{$\begin{array}{l}\text { Did Not Succeed in Making } \\
\text { Sense of OBE } \\
(\mathrm{n}=34)\end{array}$} & \multirow[b]{2}{*}{ d } & \multirow[b]{2}{*}{$\mathbf{t}$} & \multirow[b]{2}{*}{$p$} \\
\hline & $\mathrm{n}$ & $\mathbf{M}$ & SD & $\mathrm{n}$ & $\mathbf{M}$ & Sd & & & \\
\hline Absorption & 60 & 2.80 & 0.64 & 22 & 2.77 & 0.71 & 0.04 & 0.149 & 0.882 \\
\hline $\begin{array}{l}\text { Mystical } \\
\text { experiences }\end{array}$ & 60 & 3.36 & 0.61 & 22 & 3.22 & 0.73 & 0.21 & 0.878 & 0.383 \\
\hline $\begin{array}{l}\text { Pos. } \\
\text { spiritual experiences }\end{array}$ & 77 & 1.24 & 0.97 & 12 & 1.07 & 0.91 & 0.18 & 0.579 & 0.564 \\
\hline $\begin{array}{l}\text { Ego } \\
\text { loss/deconstruction }\end{array}$ & 77 & 0.65 & 0.49 & 12 & 1.00 & 0.67 & 0.60 & -2.169 & $\underset{*}{0.033}$ \\
\hline $\begin{array}{l}\text { Self-concept } \\
\text { unclarity }\end{array}$ & 137 & 2.27 & 0.78 & 34 & 2.82 & 0.84 & 0.68 & -3.685 & $\underset{* * *}{0.000}$ \\
\hline Mindfulness & 137 & 4.14 & 0.83 & 34 & 3.67 & 0.72 & 0.60 & 3.020 & $\underset{* *}{0.003}$ \\
\hline Anxiety & 137 & 6.04 & 3.77 & 34 & 8.26 & 4.62 & 0.53 & -2.946 & $\underset{* *}{0.004}$ \\
\hline
\end{tabular}

Table 5 shows the answers on the final open-ended question that is presented in this study: if and how respondents explain their OBE. The first column shows example categories of the answers, 
and the second column shows example quotes. As can be noticed, many respondents (32.3\%) have no explanation and a relatively large part of the respondents $(18 \%)$ answered this question by repeating that it was a special "experience". In addition, respondents used medical explanations $(16 \%)$, spiritual explanations (12\%) and psychological explanations or interpretations (added up 9\%). See in Table 5 other categories with a smaller number of respondents.

Table 5. (How) do you explain your OBE? $(n=171)$.

\begin{tabular}{llc}
\hline \multicolumn{1}{c}{ Example Categorization } & \multicolumn{1}{c}{ Example Quote } & n \\
\hline No explanation & $\begin{array}{l}\text { "I try to explain it rationally, that it was my own imagination (... ) } \\
\text { be true. I still don't have an explanation for this experience" } \\
\text { (women, 33 years) }\end{array}$ & 55 \\
\hline Just a special experience & "Special experience." (man, 39 years) & 30 \\
\hline $\begin{array}{l}\text { Medical explanation (medication, } \\
\text { brain, pain) }\end{array}$ & $\begin{array}{l}\text { "I think it is a combination of taking anti-depressants and having } \\
\text { trouble sleeping. For me, an out-of-body experience is purely an } \\
\text { event in the brain, caused by a combination of circumstances." }\end{array}$ & 28 \\
\hline $\begin{array}{l}\text { Spiritual explanation } \\
\text { (dimension/consciousness) }\end{array}$ & $\begin{array}{l}\text { "Explain? That's just what happens: that your soul leaves your body } \\
\text { and travels in other dimensions. (... .) " (women, 38 years) }\end{array}$ & 21 \\
\hline $\begin{array}{l}\text { Psychological origin (grief, } \\
\text { trauma, exhaustion) }\end{array}$ & $\begin{array}{l}\text { "Think it was a sort of processing of my great sorrow" (man, } \\
\text { 48 years) }\end{array}$ & 10 \\
\hline $\begin{array}{l}\text { Psychological interpretation } \\
\text { (second chance, learning) }\end{array}$ & "That you yourself are stronger than you think" (women, 40 years) & 6 \\
\hline Like a dream, fantasy & "Like a dream" (man, 53 years) & 8 \\
\hline Through meditation & "Normal. You can do a lot through meditation." (man, 65 years) & 2 \\
\hline Other & "Something that can happen" (man, 52 years old) & 11 \\
\hline
\end{tabular}

Additional analyses suggest that for respondents who do use spiritual explanations $(n=22)$ it is easier to make sense of their out-of-body experience than for respondents who do not use spiritual $(\mathrm{n}=149)$ explanations $\left(\mathrm{r}=0.25^{* *}, p<0.01 ; \mathrm{t}=-2.214, p<0.05\right)$. There is also a significant but weak negative correlation with self-concept unclarity $\left(\mathrm{r}=-0.16^{*}, p<0.05 ; \mathrm{t}=2.515, p<0.05\right)$, suggesting that these respondents are less confused about their identity,. and a weak negative correlation with anxiety $\left(\mathrm{r}=-0.17^{*} ; \mathrm{t}=2.283, p<0.05\right)$. Respondents who found the OBE "interesting" $(\mathrm{t}=2052, p<0.05)$ used significantly more spiritual explanations for the OBE $(t=2908, p<0.01)$. Finally, there is also a positive correlation between the prevalence of positive spiritual experiences (e.g., "I am illuminated by divine light and strength") and using spiritual explanations to make sense of the OBE $\left(r=0.34^{* *} ; \mathrm{t}=-3.332\right.$, $p<0.01)$.

\section{Discussion}

Should we regard "loss of self" during or after an out-of-body experience (OBE) as spiritual or scary? The short answer is: both. For some it is spiritual, for others it is scary, or scary and spiritual at the same time. It can also be regarded as neither spiritual nor scary. In the present study we tried to learn more about the mechanisms that determine when people suffer from anxiety complaints after an OBE. But before we delve into the main topic of this article, let us first deal with the possible relation between OBE and spirituality in this sample.

There are, of course, different views on what is regarded as "spiritual", and we did not ask directly: "Would you call your OBE 'spiritual'?" In order to attempt to answer this question, we therefore look in succession at the respondents' explanations of the OBE, the nature of their experience and inner changes. First of all, the data show that $12 \%$ of the respondents used spiritual explanations for their out-of-body experiences. Their answers refer to the separation of body and soul, the existence of another (spiritual) 
dimension of consciousness, or to spiritual agency (e.g., deceased relatives with personal messages for the respondents). A second indication may be their own description of the nature of the OBE. If we look at the reported experiences, we see that about $15 \%$ uses positive words (e.g., bright light, terrifying and beautiful at the same time) that are often associated with self-transcendent experiences, which can be related to spirituality (Yaden et al. 2017; Kohls and Walach 2006). A much larger number of respondents (almost half of them) agrees with descriptions referring to mystical experiences, and a smaller part had positive spiritual experiences, such as feeling the presence of spiritual beings. However, we cannot be sure if these experiences refer (only) to the OBE. Finally, a criterium for spirituality may be whether an experience leads to an inner self-transforming change (cf. Van der Lans 1998; Hood et al. 2018 referring to the James-Boisen formula). The data suggest that for about a third of the respondents the OBE has triggered a meaning making process: they could only make sense of the OBE after a while (e.g., after an emotional process, reading about OBEs and talking to others), and this may have caused inner changes. However, we do not know if respondents would "label" possible inner changes as spiritual. In addition, about half of the respondents reported that they "because of the OBE, now know something of death" or "because of the OBE, live more intensely". So, this suggests that views on life and death changed for a part of the respondents. It is clear that more systematic research is needed to answer this question, but all together the data suggest that the OBE is related to spirituality in at least a part of the respondents. However, this study also shows that there are more ways to see or respond to an OBE.

The main aim of the present study was to investigate when "loss of self" results in anxiety. Fortunately, the proportion of respondents with anxiety complaints is small. Our quantitative findings suggests that it depends on the type of "self loss" if there is a relationship with anxiety. Specifically, the results show, in line with the suggestion of Yaden et al. (2017), that there is no empirical relationship between anxiety and "loss of self" with an annhilational and relational component, a sense of connectedness with something beyond the self (i.e., mystical experiences, positive spiritual experiences). There is more anxiety in respondents (1) who experience "loss of self" with an annhilitational (dissolution of bodily self) and without a relational component (ego loss/deconstruction), but also (2) when there is less ability to (re)turn one's attention to an internal bodily state (low mindfulness), and (3) when there is a lack of self-concept unclarity (no stable coherent identity). Respondents who did not succeed in making sense of their OBE, experience more anxiety and in line with the just-mentioned results, more ego loss, lower mindfulness and (in particular) more self-concept unclarity. Below we will discuss these results in more detail.

\subsection{Making Sense of, and Explaining, an Out-of-Body Experience}

An OBE is a very intense form of self loss (seeing one's bodily self from a distance) that may evoke metaphysical thoughts but also thoughts about "the self". It was hypothesized that making sense of the experience (e.g., the meaning making process after the OBE) would reduce self-concept unclarity. Meaning making helps creating a new "life narrative" that makes it possible to develop a coherent identity: who am I in this world, what do I stand for? And vice versa, not making sense of the experience would then be related to self-concept unclarity: continuing confusion about who I am in this world, and what I stand for. This is exactly what we found. The results also showed a significant correlation with other forms of self loss, such as ego loss/de-construction and low mindfulness. It is interesting to look at the reasons some respondents mention when they were unable to make sense of their OBE. They can perhaps be interpreted as a lack of connectedness with their inner self and with the world (as we also see in ego loss/de-construction items): either they feel rejected by others (e.g., a physician), who do not want to talk to them about the OBE, or they reject the experience in themselves. The latter makes it difficult (or helps avoiding) to attune to an inner state, which may explain the lower scores on mindfulness.

The above-mentioned and other findings illustrate the importance of acknowledging the experience and communication. In particular, the respondents that made sense of the OBE after a while talked to 
others about the experience. In their qualitative research on NDEs and OBEs, Wilde and colleagues (Wilde and Murray 2009, 2010) emphasize the importance of listening and giving room to people's own understanding of the OBE. They give illustrative examples of meaning making processes after an OBE and NDE (some of which resemble the descriptions we found in our research) and the impact on one's identity.

A relatively large part of the respondents does not have an explanation for the OBE. If the respondents do have an explanation, medical and psychological explanations and interpretations (added together $25 \%$ ) are slightly more frequently mentioned than spiritual explanations (12\%). This is perhaps not strange in a largely secularized society such as the Netherlands. Zooming in on the psychological explanations and meaning making processes, it can be noticed that for a small proportion of the respondents the experience is related to pain and trauma. Some point to underlying traumatic events that they believe may have triggered the OBE (sexual abuse, grief) but also having been in a physically life-threatening situation. Moreover, thoughts and feelings after the OBE (e.g., the fear of becoming mad) may be perceived as traumatic. Although this is a small proportion of the respondents, it can be important to gauge the care needs of people who report an OBE in follow-up studies (in-depth interviews) and perhaps also in a health care context.

Our findings suggest that for respondents who do use spiritual explanations (e.g., "your soul leaves your body"), it is easier to (immediately) make sense of their OBE than for respondents who do not use spiritual explanations. Interestingly, additional $t$-tests revealed that respondents who identify as "atheist" or "searching for meaning" have significantly more (respectively, $\mathrm{t}=2.409, p<0.05 ; \mathrm{t}=3.740$, $p<0.01$ ) difficulties to (immediately) make sense of the OBE. Respondents who do use spiritual explanations also experience significantly less anxiety and more self-concept clarity. Perhaps the vocabulary that is common in certain spiritual narratives is better suited to what is actually experienced during an OBE: the feeling that one's center of awareness, often referred to as mind or spirit, is located outside the physical body. It could also be that a temporary loss of self is assessed more positively, perhaps even welcomed and expected, when using a spiritual framework (see Kohls and Walach 2007).

The inspection of the data reveals that some respondents say they cannot explain (e.g., rationally, medically, spiritually) their OBE, but still succeeded in making sense of the experience. Van Leeuwen and Van Elk (2019) argue that when scientists try to understand spiritual experiences, it is important to not only focus on abstract beliefs and attributions ("belief in God"; it was a higher spirit who protects me) that may refer to explanations but also on what experiences mean for people "personally" in their lives. Perhaps in-depth interviews and open-ended questions are better suited to portray these personal experiences and meanings. This increases the chance that explanations are not (ostensibly) directly related to spirituality (e.g., "think it was a sort of processing of my great sorrow", Table 5) but perhaps referring more to "the resolution of discontent" (cf. James-Boisen formula) may become more visible.

\subsection{Appreciation and Eloquence of the Experience Itself}

Interestingly, a relatively large group of respondents does not seem to feel the need to explain the experience. When we asked about their own explanation of the OBE, they simply repeated that it was a (very) special experience, an experience that is often positive and welcomed. This suggests that the experience itself has a certain eloquence for a part of the respondents. And a lot of respondents who could immediately make sense of the experience also mention the nature of the experience ("it was a beautiful experience"; "it had to be like this"; "the experience itself gives me answers"). This may be comparable to the experience of falling in love. It just happens, and you do not know why, but it is (scary and) beautiful. The feeling and image of such an experience may overrule the need to explain the experience.

This also raises the question of whether the nature of the experience plays (phenomenologically) an even more important role in the emergence of aftereffects than we have hitherto asserted. Positive spiritual experiences and mystical experiences (relational component: a sense of connectedness with something beyond the self, Yaden et al. 2017) were not correlated to anxiety complaints and 
positive spiritual experiences were associated with less perceived confusion because of the OBE and lower anxiety complaints in the regression analysis (Table 2b). A follow-up question in future studies could be whether people are simply unlucky when the experience has no positive relational component or whether this is influenced by other factors (see Cassol et al. 2019 for a recent study on distressing NDE accounts).

\section{3. "Attention Regulation" as a Skill?}

"Attention" seems to play an interesting role in the occurrence of self-transcendent spiritual experiences, as well as anxiety. As expected, anxiety was higher in OBE respondents with lower mindfulness scores, which may imply that they have difficulties to return or attune to an internal state or bodily self (cf. Blaser et al. 2014). In OBErs a general weaker sense of embodiment ("loss of bodily self") as well as higher scores on absorption are not unusual. Absorption, having episodes of "total" attention that fully engage one's perceptual, imaginative, ideational resources, was positively correlated to mystical experience (see also Granqvist et al. 2012; Lifshitz et al. 2019), as well as to lower mindfulness and anxiety. However, regression analysis revealed that absorption did not contribute to anxiety in a model that also includes low mindfulness. This suggests that some OBErs who suffer from anxiety complaints find it hard to be mindful (attention to the body and the here-and-now) which may be partly due to trauma or a distressing OBE but perhaps also to higher scores on the trait absorption (attention away from the body and the here-and now).

In the present study, one person reported that it is quite common to have an out-of-body experience during a meditation, which may indicate that extending one's sense of self can be achieved through practice. A recent study from De Castro (2015) shows that practicing meditation increases both mindfulness (related to less anxiety in the present study) and mystical experiences (related to absorption in the present study). Although one may think of absorption and mindfulness as the opposite when you look at the direction of one's attention (i.e., attention turned from the body and the here-and-now in absorption versus attention turned towards the body and the here-and-now in mindfulness), some people may score high on both absorption and mindfulness, perhaps because they have (trained) a certain flexibility in the regulation of where they turn their attention to. This could be an interesting topic for future studies.

\subsection{Limitations}

This study is not without limitations. First of all, we now have doubts about the formulation of the open-ended question "Describe your most impressive OBE.". Some people have multiple OBEs, and we wanted them to focus only on one experience. However, the question was a bit suggestive because it implied that it was an impressive OBE. One person said it was not. It would have been better to ask the question differently, for example: "If you have had multiple OBEs, describe one that you remember best". Secondly, because we wanted to reduce the length of the questionnaire we decided to work with subsamples, which means that only half of the respondents answered questions about absorption, mysticism (subsample 1), positive spiritual experiences and ego loss/deconstruction (subsample 2). Nevertheless, we dare to say with conviction that it has been made plausible enough that there is no reason to assume that self loss with a relational component is related to anxiety complaints and that there is reason to assume that ego loss, low mindfulness and self-concept unclarity are all associated with anxiety. That does not alter the fact that it would be good to replicate our findings in a larger sample. Thirdly, non-experimental, non-longitudinal, correlational research cannot prove causation. We can only conclude that we found a relationship between some forms of self loss and anxiety complaints. Pre-measurement and post-measurement would provide more insight into cause-effect relationships, but that is difficult in the study of spontaneous experiences such as OBEs. We included some questions about aftereffects (e.g., "I got scared") and meaning making after the OBE (Did you make sense of the OBE?), which were found to be related to self loss measures as well as 
anxiety complaints. This makes it perhaps more plausible that the OBE triggers anxiety in a proportion of the respondents.

Finally, it is clear that there is a cultural component involved when we talk about "the self" and "self loss". We have attempted to operationalize different conceptualizations of self loss using psychological concepts constructed by Western researchers. We assumed, for instance, that in a largely secularized country such as the Netherlands (among spiritual non-practioners, cf. Kohls and Walach 2007), ego loss/deconstruction would be related to anxiety and we hypothesized that self-concept unclarity, as a result of not making sense of the OBE, would be associated with more anxiety. However, research on self-concept clarity suggests that self-confidence depends much less on having a stable or coherent self in non-western cultures than in western cultures (Campbell et al. 1996). The question is therefore whether our findings could be replicated in a non-western country with more spiritual or religious practitioners.

\subsection{To Conclude}

Despite these limitations, the present study helped gain a little more insight into when "loss of self" in a sample of OBEs is related to anxiety (fortunately not often), and it suggests that it relates to the type of "loss of self" that is experienced. Hopefully, this research has done justice to the variety of OBE experiences, interpretations and explanations of our respondents. The present study may also invite to further reflect on the concept of "self" and "self loss" and everything we, as humans, mean by it when we try to describe ourselves and our experiences (e.g., bodily self, mind, soul, ego, identity).

Funding: A part of this research (i.e., data collection, overhead) was funded by Stichting de Zaaier (Utrecht, The Netherlands).

Acknowledgments: A special word of thanks goes to Hans Gerding, who shared his knowledge with me about exceptional experiences and helped create the questionnaire and approach the respondents. Without him doing this project and writing the article would not have been possible. Thanks to Maggie Eybrechts, Barbara van der Vlugt and Joris Neven, who have assisted in creating the questionnaire and preparing the dataset. Discussing the topic with them has also been a great help in working on this project.

Conflicts of Interest: The author declares no conflict of interest.

\section{References}

Acunzo, David, Etzel Cardeña, and Devin B. Terhune. 2020. Anomalous experiences are more prevalent among highly suggestible individuals who are also highly dissociative. Cognitive Neuropsychiatry 25: 179-89. [CrossRef] [PubMed]

Alvarado, Carlos S. 2000. Out-of-body experiences. In Varieties of Anomalous Experience: Examining the Scientific Evidence. Edited by Etzel Ed Cardeña, Steven Jay Ed Lynn and Stanley Ed Krippner. Washington, DC: American Psychological Association, pp. 183-218. [CrossRef]

Aspell, Jane, and Olaf Blanke. 2009. Understanding the out-of-body experience from a neuroscientific perspective. In Perspectives on Out of Body and Near Death Experiences. Edited by Craig D. Murray. Hauppauge: Nova Science Publishers, chp. 5. pp. 73-88. ISBN 978-1-60741-705-7.

Baer, Ruth A. 2003. Mindfulness training as a clinical intervention: A conceptual and empirical review. Clinical Psychology: Science and Practice 10: 125-43. [CrossRef]

Bigler, Monica, Greg J. Neimeyer, and Elliott Brown. 2001. The divided self revisited: Effects of self-concept clarity and self-concept differentiation on psychological adjustment. Journal of Social and Clinical Psychology 20: 396-415. [CrossRef]

Blackmore, Susan. 1982. Beyond the Body. An Investigation of Out-of-Body Experiences. Chicago: Chicago Review Press, ISBN 0897333446.

Blaser, Klaus, Milena Zlabinger, Martin Hautzinger, and Thilo Hinterberger. 2014. The relationship between mindfulness and the mental self-boundary: Validation of the Boundary Protection Scale-14 (BPS-14) and its correlation with the Freiburg Mindfulness Inventory (FMI). Journal of Educational and Developmental Psychology 4: 155-62. [CrossRef] 
Braud, William. 2012. Health and well-being benefits of exceptional human experiences. In Mental Health and Anomalous Experience. Edited by C. D. Murray. New York: Nova Science Publishers, pp. 107-24.

Brown, Kirk, and Richard Ryan. 2003. The Benefits of Being Present: Mindfulness and Its Role in Psychological Well-Being. Journal of Personality and Social Psychology 84: 822-48. [CrossRef]

Campbell, Jennifer D., Paul D. Trapnell, Steven J. Heine, Ilana M. Katz, Loraine F. Lavallee, and Darrin R. Lehman. 1996. Self-concept clarity: Measurement, personality correlates, and cultural boundaries. Journal of Personality and Social Psychology 70: 141-56. [CrossRef]

Cassol, Helena, Charlotte Martial, Jitka Annen, Géraldine Martens, Vanessa Charland-Verville, Steve Majerus, and Steven Laureys. 2019. A systematic analysis of distressing near-death experience accounts. Memory 27: 1122-29. [CrossRef] [PubMed]

Coleman, Thomas J., III, James E. Bartlett, Jenny M. Holcombe, Andrew Atkinson, Sally B. Swanson, Christopher F. Silver, and Ralph W. Hood Jr. 2019. Absorption, Mentalizing, and Mysticism: Sensing the Presence of the Divine. Journal for the Cognitive Science of Religion 5: 63-84. [CrossRef]

Crawford, John Robertson, J. D. Henry, C. Crombie, and E. P. Taylor. 2001. Normative data for the HADS from a large non-clinical sample. British Journal of Clinical Psychology 40: 429-34. [CrossRef]

De Castro, John M. 2015. Meditation has stronger relationships with mindfulness, kundalini, and mystical experiences than yoga or prayer. Consciousness and Cognition 35: 115-27. [CrossRef]

Granqvist, Pehr, Berit Hagekull, and Tord Ivarsson. 2012. Disorganized attachment promotes mystical experiences via a propensity for alterations in consciousness (absorption). International Journal for the Psychology of Religion 22: 180-97. [CrossRef]

Greyson, Bruce. 1994. Near-death experiences and satisfaction with life. Journal of Near-Death Studies 13: 103-8.

Hood, Ralph W., Jr. 1975. The construction and preliminary validation of a measure of reported mystical experience. Journal for the Scientific Study of Religion 14: 29-41. [CrossRef]

Hood, Ralph W., Jr., Peter C. Hill, and Bernard Spilka. 2018. The Psychology of Religion: An Empirical Approach. New York: Guilford Publications, ISBN 9781462535989.

Irwin, Harvey. 1986. Perceptual perspective of visual imagery in OBEs, dreams and reminiscence. Journal of the Society for Psychical Research 53: 210-17.

James, William. 1985. The Varieties of Religious Experience. Cambridge: Harvard University Press. First published 1902.

Kohls, Niko, and Harald Walach. 2006. Exceptional experiences and spiritual practice: A new measurement approach. Spirituality and Health International 7: 125-50. [CrossRef]

Kohls, Niko, and Harald Walach. 2007. Psychological distress, experiences of ego loss and spirituality: Exploring the effects of spiritual practice. Social Behavior and Personality: An International Journal 35: 1301-16. [CrossRef]

Lifshitz, Michael, Michiel van Elk, and Tanya M. Luhrmann. 2019. Absorption and spiritual experience: A review of evidence and potential mechanisms. Consciousness and Cognition 73: 102760. [CrossRef]

Marlatt, G. Alan, and Jean L. Kristeller. 1999. Mindfulness and meditation. In Integrating Spirituality into Treatment: Resources for Practitioners. Edited by William. R. Miller. Washington, DC: American Psychological Association, pp. 67-84. [CrossRef]

Murray, Craig, and Jezz Fox. 2005. Dissociational body experiences: Differences between respondents with and without prior out-of-body experiences. British Journal of Psychology 96: 441-56. [CrossRef]

Paloutzian, Raymond. 2016. Invitation to the Psychology of Religion. New York: Guilford Publications.

Paloutzian, Raymond, and Crystal Park. 2013. Directions for the future of psychology of religion and spirituality: Research advances in methodology and meaning systems. In Handbook of the Psychology of Religion and Spirituality. New York: The Guilford Press, pp. 651-65.

Saroglou, Vassilis. 2011. Believing, bonding, behaving, and belonging: The big four religious dimensions and cultural variation. Journal of Cross-Cultural Psychology 42: 1320-40. [CrossRef]

Taves, Ann. 2008. Ascription, attribution, and cognition in the study of experiences deemed religious. Religion 38: 125-40. [CrossRef]

Tellegen, Auke, and Gilbert Atkinson. 1974. Openness to absorbing and self-altering experiences ("absorption"), a trait related to hypnotic susceptibility. Journal of Abnormal Psychology 83: 268. [CrossRef]

Tomlinson, Eve R., Omar Yousaf, Axel D. Vittersø, and Lauraine Jones. 2018. Dispositional Mindfulness and Psychological Health: A Systematic Review. Mindfulness 9: 23-43. [CrossRef] [PubMed] 
Van der Lans, Johannes. 1998. Kernervaringen, Esthetische Emotie en Religieuze Betekenisgeving. Katholieke Universiteit: Nijmegen, The Netherlands.

Van Leeuwen, Neil, and Michiel Van Elk. 2019. Seeking the supernatural: The Interactive Religious Experience Model. Religion, Brain Behavior 9: 221-51. [CrossRef]

Wilde, David. 2011. Finding Meaning in Out-of-Body Experiences: An Interpretative Phenomenological Analysis. Ph.D. thesis, University of Manchester, Manchester, UK.

Wilde, David J., and Craig D. Murray. 2009. The evolving self: Finding meaning in near-death experiences using Interpretative Phenomenological Analysis. Mental Health, Religion Culture 12: 223-39. [CrossRef]

Wilde, David, and Craig D. Murray. 2010. Interpreting the Anomalous: Finding Meaning in Out-of-Body and Near-Death Experiences. Qualitative Research in Psychology 7: 57-72. [CrossRef]

Yaden, David Bryce, Jonathan Haidt, Ralph W. Hood Jr., David R. Vago, and Andrew B. Newberg. 2017. The varieties of self-transcendent experience. Review of General Psychology 21: 143-60. [CrossRef]

Zigmond, Anthony S., and R. Philip Snaith. 1983. The hospital anxiety and depression scale. Acta Psychiatrica Scandinavica 67: 361-70. [CrossRef]

Publisher's Note: MDPI stays neutral with regard to jurisdictional claims in published maps and institutional affiliations.

(C) 2020 by the author. Licensee MDPI, Basel, Switzerland. This article is an open access article distributed under the terms and conditions of the Creative Commons Attribution (CC BY) license (http://creativecommons.org/licenses/by/4.0/). 